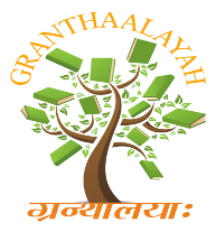

INTERNATIONAL JOURNAL OF RESEARCH GRANTHAALAYAH A knowledge Repository

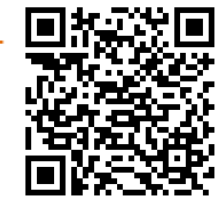

\title{
FRAMING GM CROPS AS A SOLUTION FOR GLOBAL FOOD SECURITY
}

\author{
Reddy,P.B \\ Government PG College, Ratlam
}

\begin{abstract}
Genetically Modified organisms (GMOs) are a tool of solution in helping to tackle the challenge of global food security for ever growing population. With global population expected to grow by $40 \%$ in the next few decades, agriculture will need to become more productive and more sustainable in order to keep pace with rapidly increasing demands. The current biotechnology permits to alter the genetic makeup of living organisms to produce much quicker and beneficial results. The present study is aimed to evaluate the economic, environmental and nutritive benefits of transgenic crops. We have reviewed many articles from various journals, blogs and media clips related to the subject. Results indicate that the use of GMOs have many potential benefits that include increased crop production, improved nutrition, and drought tolerance, reduced fertilizers and pesticides, better environmental condition, improved economic benefits and improvement in fruit storage. Conversely, there are few concerns about possible unpredicted adverse health effects, environmental damage, gene pollution and business exploitation. Results also indicate the towering costs and uncertainty about the guidelines of GMOs have slowed the rate of innovation of new qualities and prevented set ups and major corporate sectors from developing many second-generation varieties to facilitate the improvement of our well-being.
\end{abstract}

Keywords:

Food security, Global population, GMOs, Sustainable agriculture.

\section{INTRODUCTION}

Humans have modified food plants and animals for many centuries by selection breeding. Hunger and lack of nutrition is no longer a reality in all over the world. With the Green Revolution that Norman Borlaug fathered, the then very real danger that tens of millions dying has withdrawn. Borlaug work gave the agriculture scientists a window in which they could develop new technologies to feed the ever growing population of the planet (Gaud, William S.1968). According to the World Food Program (WFP), about 800 million people or one in nine people on this planet don't have sufficient food to lead a healthy and active life (http://www.wfp.org). Experts predict that the next global food crisis may occur within four to five years if appropriate measures not taken.

Uncontrolled population growth, increasing conflict and dislocation, natural calamities and appearance of major outbreaks are some of the factors that will multiple difficulties of global food security over the coming years. In the face of these facts, any technique that can improve food production both in quality and quantity would be a welcome development. To counteract the 
coming problem, it is very important to try novel and bold solutions across the agricultural food chain, including the gene modification of crops. While genetically modified (GM) crops could be our best hope for feeding an increasingly hungry planet, they need to be developed within a regulatory framework that takes potential risks into account and protects farmers, consumers and the environment (http://www.earthisland.org/journal). Therefore, we aimed to highlight the importance of GMOs to solve the world's two major problems of food security and climate change. On the other hand, others concerns like possible unpredicted health effects, environmental damage, gene pollution and business exploitation were also discussed.

\section{METHODOLOGY}

This research review paper is based on information from the fact sheets from USDA, green peace, and Monsanto literature bases. Information was also acquired from blogs, web sites and editorials dealing with the GM crops. Selected references can be found in the Appendices of the working manuscript. Additionally, many press reports have been reviewed on a regular basis.

\section{RESULTS AND DISCUSSION}

Farmers have extensively accepted GM technology. From 1996 to 2013, the total surface area of land cultivated with GM crops increased from 17,000 square kilometers $(4,200,000$ acres) to $1,750,000 \mathrm{~km}^{2}$ (432 million acres) (ISAAA 2013).10\% of the world's croplands were planted with GM crops in 2010. In the US, by 2014, 94\% of the planted area of soybeans, $96 \%$ of cotton and $93 \%$ of corn were genetically modified varieties (http://www.ers.usda.gov/data). GM crops are also expanding rapidly in developing countries and approximately 18 million farmers grew 54\% of worldwide GM crops in developing countries in 2013(ISAAA, 2013).

There is extensive scientific consent that food on the market derived from GM crops causes no bigger threat to human health than usual food (Ronald, Pamela,2011), AAAS, 2012, FAO, 2004). GM crops also provide a number of ecological benefits (Andrew Pollack.2010).

Yield: Recent research reports concluded that GM crops' effects of agronomic and economic impacts on farming were positive. They found that herbicide-tolerant crops have lower production costs, while for insect-resistant crops the reduced pesticide use was compensate by elevated seed prices, leaving on the whole production costs about the same (Klümper, W; Qaim, M,2014) ://www.economist.com/news).

Crop yields increased $9 \%$ for herbicide tolerance and $25 \%$ for insect resistance. Farmers who implemented GM crops made $69 \%$ higher profits than those of traditional farmers. The study also found that GM crops help farmers in budding countries, increasing yields by 14 percentage points (www.economist.com/news). The investigators considered some studies that were not peerreviewed, and a few that did not report sample sizes. They tried to correct for publication unfairness, by considering sources beyond academic journals. Individually, their study concluded that the funding source did not influence study results (www.economist.com/news).

Traits: GM crops grown have been modified with various traits like improved storage life, disease resistance, stress resistance, herbicide resistance, pest resistance, production of useful goods such as biofuel or drugs, and ability to absorb toxins and for use in bioremediation of pollution. The earliest genetically tailored crop approved for sale in the U.S. was the Flavr Savr tomato, which had a longer shelf life (Bruening, G and Lyons, J. M. (2000) but due to possible adverse health effects it is no longer on the market. In November 2014, the USDA approved a GM potato that checks yellowing (USDA, 2014). Recently in February 2015 Arctic Apples were approved by the 
USDA (Pollack, A.2015) becoming the first genetically modified apple approved for US sale (Tennille, Tracy (2015).

Stress resistance: Scientist engineered plants to tolerate non-biological stressors such as drought (Andrew Pollack,2014, Federal Register,2013, http://www.gmocompass.org/eng/news/371.docu.html) -frost, Lundmark, C. 2006, Staff,2011) high soil salinity (Banjara, Manoj;et al,2012, Sara Abdulla,1999) and nitrogen starvation (Rennie, Rob and Heffer, Patrick,2010) were in development. In 2011, Monsanto's Drought Gard maize of Monsanto became the first drought-resistant GM crop to receive US marketing approval in 2011 (Michael Eisenstein, 2013).

Herbicides (Glyphosate); Glyphosate is the active element in Roundup and other herbicide products that kills plants by interfering with the shikimate pathway in plants (by inhibiting the enzyme 5-enolpyruvylshikimate-3-phosphate synthase (EPSPS). This shikimate pathway is missing in animals, which instead acquire aromatic amino acids from their diet. This trait was developed because the herbicides used on crops at the time were highly toxic and not even effective against many weed varieties. Thus, developing crops that could resist spraying with glyphosate would both reduce environmental and health risks, and give an agricultural edge to the farmer (Carpenter J. and Gianessi L. (1999). Recently tobacco plants have been modified to be resistant to the herbicide bromoxynil. (Debora MacKenzie (1994). Plants engineered for resistance to various herbicides to permit farmers to use a mixed group of two, three, or four different chemicals are under development to fight growing herbicide resistance.Recently in October 2014, genetically engineered a variety of maize of Dow was approved by US EPA which claims resistant to both glyphosate and 2,4-D (ISAAA,2015). Similar crops like maize and soybeans had approved in 2014 with the mutation by USDA (http://www.smithsonianmag.com/smart-news).

Pest resistance: Many crops like tobacco, corn, rice and other crops have been genetically modified to express genes encoding for insecticidal proteins from Bacillus thuringiensis (Bt) Vaeck, M et al,1987) while potatoes, papaya, and squash have been genetically modified to resist viral pathogens such as cucumber mosaic virus which infects a ample variety of plants (NAS,2001). In 1990s, a GM potato that was anti to the Colorado potato beetle was withdrawn due to poor sales and big opposition from buyers and consumer (Andrew Pollack, 2014). Recently FDA approved the first genetically modified plant-produced pharmaceutical, for the treatment of Gaucher's Disease (www.globes.co.il). Tobacco plants have been modified to produce therapeutic antibodies (Jha, Alok 2012).

Bioremediation: Genetically modified organisms have been used for bioremediation of contaminated soils and water with mercury, selenium and other organic pollutants such as polychlorinated biphenyls (PCBs) Meagher, RB (2000). In recent times Scientists from University of York have developed a weed (Arabidopsis thaliana) that contains genes from bacteria which can clean TNT and RDX-explosive soil contaminants (Strange, Amy2011). Marine environments are particularly susceptible due to oil spills. Besides man made pollution, millions of tons of petroleum regularly enter the marine environment from natural seepages. A group of specialists, recently discovered the so-called hydrocarbonoclastic bacteria (HCCB) that may offer useful genes to for degradation of hydrocarbons from petroleum products (Martins VAP (2008).

Controversy and Regulation: GM foods are controversial and the subject of protests, legislation, court action and scientific disputes. The controversies involve consumers, biotechnology companies, governmental regulators, non-governmental organizations (NGOs) and scientists (Ronald, Pamela (2011). The key areas are whether GM food should be labeled, the role of government regulators, the effect of GM crops on health and the environment, the effects of 
pesticide use and resistance, the impact on farmers, and their roles in feeding the world and energy production. The regulation of genetic engineering concerns the advances taken by governments to evaluate and handle the risks related with the development and use of genetically modified crops. There are diversities in the regulation of GM crops between countries. Regulation varies in a given country depending on the proposed use of each product. Worries include mixing of genetically engineered and non-genetically modified products in the food supply (CIEH, 2015), effects of GMOs on the environment (CAPE, 2013) and the rigidity of the regulatory process (AMA,2012).

\section{CONCLUSIONS}

In conclusion, not any of studies proves or even convincingly suggests that GMOs can be harmful to human health. The majority are either clearly flawed or are not scientific studies. This research work also confirms that despite impact heterogeneity the usual agronomic and economic benefits of genetically engineered (GE) crops are huge and noteworthy. Impacts differ especially by GE crop trait and geographic province. Yield gains and pesticide reductions are larger for GE crops than traditional crops. Yield and farmer profit gains are also higher. The present study used better data and methods than former studies. Results also indicate the soaring costs and uncertainty about the guidelines of GMOs have slowed the rate of innovation of new qualities and prevented set ups and major corporate sectors from developing many second-generation varieties to facilitate the improvement of our well-being. The application of GM technology thus moves towards as solution to the numerous food security challenges facing the world at large. Widespread public awareness campaigns are required to address the concerns of consumers and to highlight biosafety measures and the advantages of genetically modified crops.

\section{REFERENCES}

1. AAAS, 2012.American Association for the Advancement of Science (AAAS), Board of Directors .2012. Statement by the AAAS Board of Directors On Labeling of Genetically Modified Foods, and associated Press release: Legally Mandating GM Food Labels Could Mislead and Falsely Alarm Consumers.

2. AMA.2012. American Medical Association. Report 2 of the Council on Science and Public Health: Labeling of Bioengineered Foods.To better detect potential harms of bioengineered foods, the Council believes that pre-market safety assessment should shift from a voluntary notification process to a mandatory requirement." 7-7.

3. Banjara, Manoj; Longfu Zhu; Guoxin Shen; Paxton Payton; Hong Zhang.2012. "Expression of an Arabidopsis sodium/proton antiporter gene (AtNHX1) in peanut to improve salt tolerance". Plant Biotechnol Rep 6: 59-67.

4. Bruening, G.; Lyons, J. M.2000.The case of the FLAVR SAVR tomato. California Agriculture 54 (4): 6-7.

5. CAPE, 2013.Canadian Association of Physicians for the Environment.Statement on Genetically Modified Organisms in the Environment and the Marketplace.

6. Carpenter J. \& Gianessi L. 1999. Herbicide tolerant soybeans: Why growers are adopting Roundup Ready varieties AgBioForum, 2(2), 65-72.

7. CIEH,2015.https://en.wikipedia.org/wiki/Chartered Instituteof Environmental_Health

8. Debora MacKenzie.1994. "Transgenic tobacco is European first. New Scientist.

9. FAO, 2004. State of Food and Agriculture 2003-2004. Agricultural Biotechnology: Meeting the Needs of the Poor. 
10. Federal Register. 2013. J.R. Simplot Co.; Availability of Petition for Determination of Nonregulated Status of Potato Genetically Engineered for Low Acrylamide Potential and Reduced Black Spot Bruis.

11. Gaud, William S.1968.http://www.agbioworld.org/biotech-info/topics/borlauggreen.html.

12. http://www.earthisland.org/journal

13. http://www.economist.com/news/science-and-technology/21630961-biggest-study-so-farfinds-gm-crops-have-large-widespread-benefits-field

14. http://www.ers.usda.gov/data-products/adoption-of-genetically-engineered-crops-inthe-us.aspx

15. http://www.globes.co.il/en/article-1000745325

16. http://www.gmo-compass.org/eng/news/371.docu.html

17. http://www.smithsonianmag.com/smart-news

18. http://www.wfp.org

19. IRRI,2012.About Golden Rice. International Rice Research Institute.

20. ISAAA 2013 Annual Report Executive Summary, Global Status of Commercialized Biotech/GM Crops: 2013. ISAAA Brief 46-2013, Retrieved 6 August 2014.

21. ISAAA.2015. GM Approval Database Gene list: http://www.isaaa.org/gmapprovaldatabase/gene/

22. Jha, Alok .2012. Julian Ma: I'm growing antibodies in tobacco plants to help prevent HIV.The Guardian. 2012

23. Klümper, W; Qaim, M.2014. "A Meta-Analysis of the Impacts of Genetically Modified Crops. PLoS ONE, 9 (11): e111629.

24. Lundmark, C. 2006. "Searching Evolutionary Pathways: Antifreeze Genes from Antarctic Hairgrass. BioScience 56.(6): 552.

25. Martins VAP.2008. "Genomic Insights into Oil Biodegradation in Marine Systems". Microbial Biodegradation: Genomics and Molecular Biology. Caister Academic Press. ISBN 978-1-904455-17-2.

26. Meagher, RB.2000. "Phytoremediation of toxic elemental and organic pollutants". Current Opinion in Plant Biology 3 (2): 153-162.

27. Michael Eisenstein .2013.Plant breeding: Discovery in a dry spell. Nature 501, S7-S9.

28. NAS,2001. National Academy of Sciences.2001. Transgenic Plants and World Agriculture. Washington: National Academy Press.

29. Pollack, A. 2015. "Gene-Altered Apples Get U.S. Approval. New York Times, 2015.

30. Rennie, Rob and Heffer, Patrick.2011.Anticipated Impact of Modern Biotechnology on Nutrient Use Efficiency, TFI/FIRT Fertilizer Outlook and Technology Conference 16-18 November 2010, Savannah (GA), 2011.

31. Ronald, Pamela 2011. "Plant Genetics, Sustainable Agriculture and Global Food Security. Genetics 188 (1): 11-20.

32. Ronald, Pamela 2011. "Plant Genetics, Sustainable Agriculture and Global Food Security.Genetics.188 (1):

33. Tennille, Tracy (Feb 13, 2015). "First Genetically Modified Apple Approved for Sale in U.S. Wall Street Journal. Retrieved Feb 2015. 